\title{
ANALISIS PENGARUH PENGGUNAAN SISTEM INFORMASI AKADEMIK (SIA) ONLINE TERHADAP KEPUASAN MAHASISWA
}

\author{
Silvia Ratna \\ Fakultas Teknologi Informasi, Universitas Islam Kalimantan \\ Muhammad Arsyad Al Banjari Banjarmasin \\ Email : via.Borneo@gmail.com
}

\begin{abstract}
Online academic information systems is a service to student to make it easy the transaction akademic, with the existence of an academic information system, students can carry out academic transactions wherever they are on the condition of being connected to the internet the number of SIA services that can be given has an impact on student satisfaction. This research aims (1) to find out what academic services are provided using the Online Academic Information System (SIAO) that has been implemented in Islamic University of Kalimantan (2) To determine the level of student satisfaction with the enactment of Academic Information Systems (3) To find out the influence use of the Online Academic Information System (SIAO) for Students (4) Can provide input and strategic steps regarding the application of the Online Academic Information System at the University The total population in this study were 100 students of the Faculty of Information Technology The population of this study were 100 students using online academic information systems at the Faculty of Information Technology, Islamic University of Kalimantan. Data analysis techniques used descriptive statistical analysis and inferential statistics using Smart PLS
\end{abstract}

Keywords: Sia Online, Satisfaction, users

\begin{abstract}
ABSTRAK
Sistem Informasi akademik Online merupakan layanan yang diberikan kepada mahasiswa untuk memudahkan dalam bertransaksi akademik, dengan adanya sistem informasi akademik mahasiswa dapat melaksanakan transaksi akademik dimanapun berada dengan syarat terhubung dengan internet. Banyaknya pelayanan SIA yang bisa diberikan berdampak pada kepuasan mahasiswa. . Penelitian ini bertujuan (1) Untuk mengetahui pelayanan akademik apa saja yang di berikan dengan menggunakan Sistem Informasi Akademik Online (SIAO) yang sudah diberlakukan di Universitas islam Kalimantan (2) Untuk mengetahui tingkat kepuasan mahasiswa dengan diberlakukannya Sistem Informasi Akademik (3) Untuk mengetahui pengaruh penggunaan Sistem Informasi Akademik Online (SIAO) terhadap Mahasiswa(4) Dapat memberikan masukan-masukan dan langkah-langkah strategis berkenaan dengan diberlakukannya Sistem Informasi Akademik Online di Universitas. Total populasi dalam penelitian ini adalah 100 mahasiswa Fakultas Teknologi Informasi Populasi penelitian ini adalah 100 mahasiswa pengguna sistem informasi akademik online di Fakultas Teknologi Informasi universitas islam kalimantan Teknik analisis data menggunakan analisis statistik deskripstif dan statistik inferensial yang menggunakan Smart PLS .
\end{abstract}

Kata Kunci : Sia Online, Kepuasan, pengguna 


\section{PENDAHULUAN}

Dunia pendidikan terus dituntut untuk meningkatkan kualitas dan pelayanan dalam rangka menuju Perguruan Tinggi Bertatakelola baik, baik kualitas sumberdaya manusia yang terdiri dari tenaga pendidik dan tenaga kependidikan maupun fasilitas pendidikan dan fasilitas penunjang yang dibutuhkan dalam proses belajar mengajar. Untuk meningkatkan kualitas tersebut maka perlu mengembangkan proses akademik yaitu dengan diberlakukan sistem informasi akademik dan untuk lebih memudahkan maka ditingkatkan pelayanan menjadi sistem informasi akademik online. Universitas islam kalimantan sudah menerapkan sistem informasi akademik namun perlu diteliti dan dianalisis apakah mahasiswa yang merupakan pengguna SIA Online merasa puas dan merasa dimudahkan dengan diterapkannya SIA Online tersebut.Sistem Informasi Akademik (SIA) di Universitas Islam Kalimantan merupakan bentuk layanan kepada mahasiswa secara online mulai input data mahasiswa registrasi sampai mahasiswa menyelesaikan studinya (lulus), Kartu Rencana Studi (KRS), Kartu Hasil Studi (KHS), Transkrip Nilai. Berdasarkan kenyataan inilah peneliti ingin menganalisis seberapa besar Sistem Informasi Akademik dapat memberikan kepuasan terhadap mahasiswa. Rumusan permasalahan ini sebagai berikut : (1) Pengaruh apa yang didapatkan oleh mahasiswa ketika menggunakan sia online ? (2) Bagaimana kepuasan mahasiswa dengan adanya Sistem Informasi Akademik online di Universitas Islam Kalimantan? (3) Apa saja Kemudahan yang didapatkan dengan adanya Sistem Informasi Akademik di Universitas Islam Kalimantan Banjarmasin? (4) Hambatan apa saja yang dialami oleh user dalam penggunaan Sistem Informasi Akademik online di Universitas Islam Kalimantan Banjarmasin?

\section{LANDASAN TEORI}

\subsection{Teknologi Informasi}

Penggunaan teknologi informasi dan komunikasi melalui sistem informasi bukan saja akan meningkatkan kualitas serta kecepatan informasi yang dihasilkan bagi manajemen, namun dengan adanya teknologi informasi dan komunikasi yang sesuai akan dapat menciptakan suatu sistem informasi manajemen yang mampu meningkatkan integrasi antar fungsional di organisasi. Untuk menyajikan teknologi informasi dan komunikasi yang cepat dan akurat, maka dalam proses pengolahan data harus dilakukan secara terkomputerisasi dalam sebuah sistem yang biasa disebut sistem informasi. Dengan dilakukannya proses pengolahan data secara terkomputerisasi, maka pekerjaan-pekerjaan pengolahan data tersebut bisa dilakukan secara efektif dan efisien.

\subsection{Sistem Informasi}

Penggunaan teknologi informasi dan komunikasi melalui sistem informasi bukan saja akan meningkatkan kualitas serta kecepatan informasi yang dihasilkan bagi manajemen, namun dengan adanya teknologi informasi yang sesuai akan menciptakan sitem informasi manajemen yang mampu meningkatkan integrasi antar fungsional di organisasi. Definisi umum sistem informasi adalah: "Sebuah sistem yang terdiri atas rangkaian subsistem informasi terhadap pengolahan data untuk menghasilkan informasi yang berguna dalam pengambilan keputusan."

\subsection{Sistem Informasi Akademik}

Sistem informasi akademik online adalah aplikasi yang digunakan mahasiswa untuk melakukanadministrasi akademiknya, misalnya pengisian Kartu Rencana study(KRS) secara online,melihat dan menampilkan nilai pada kartu hasil Study (KHS) secara online serta menampilkan data transkrip nilai.

\subsection{Kepuasan Pengguna SIA Online}

Kepuasan mempunyai peran yang sangat sentral dalam penggunaan dan pengembangan sistem informasi. Pemahaman pengguna merupakan faktor penting yang menentukan kepuasan penggunaan sistem informasi (McKeen et al.,1994) ; (Doll dan Deng, 2001); (Guimaraes et al., 2003); (Suryaningrum, 2003). Kepuasan pengguna merupakan bentuk persepsi individu terkait apa yang dirasakan pada saat menggunakan sistem informasi sehingga memberikan manfaat pada 
pekerjaannya. Partisipasi pengguna merupakan upaya untuk mencapai kepuasan pengguna agar keberhasilan dalam pengembangan sistem dapat dicapai.

Kebutuhan pengguna terhadap sistem informasi sangat tinggi. Hal tersebut terjadi karena dapat meringankan tugas-tugas pekerjaan yang dilakukan individu. Ketika kebutuhan akan sistem informasi tinggi maka kepuasan yang dirasakan oleh individu akan tinggi pula. Kepuasan pengguna (user satisfaction) merupakan ukuran kesuksesan sistem informasi yang bersifat perceptual dan sangat subyektif. Penentuan sebuah sistem informasi yang baik atau buruk sangat tergantung pada apa yang dirasakan oleh pengguna setelah mengoperasikan sistem informasi tersebut. Penggunaan bergantung pada evaluasi individu sebagai pelaku pengguna sistem informasi.

\section{METODE PENELITIAN}

Sampel yang digunakan dalam penelitian ini pengguna Sistem informasi Akademik Online.

\begin{tabular}{|c|c|c|}
\hline Variabel & Indikator & Sumber \\
\hline \multirow{5}{*}{$\begin{array}{l}\text { Penggunaan } \\
\text { (X1) }\end{array}$} & Mudah dipahami $\left(\mathrm{Y}_{2.1}\right)$ & \multirow{5}{*}{$\begin{array}{l}\text { Goodhue dan } \\
\text { Thompson } \\
\text { (1995) dan } \\
\text { Casalo et al. } \\
\text { (2005) }\end{array}$} \\
\hline & $\begin{array}{cc}\text { Mudah } & \text { digunakan } \\
\left(\mathrm{Y}_{2.2}\right) & \\
\end{array}$ & \\
\hline & $\begin{array}{l}\text { Mudah diimplementasi } \\
\left(\mathrm{Y}_{2.3}\right)\end{array}$ & \\
\hline & $\begin{array}{c}\text { Mudah } \\
\left(\mathrm{Y}_{2.4}\right)\end{array}$ & \\
\hline & $\begin{array}{c}\text { Mudah dilakukan } \\
\text { maintenance }\left(\mathrm{Y}_{2.5}\right)\end{array}$ & \\
\hline \multirow{3}{*}{$\begin{array}{l}\text { Kepuasan } \\
\text { (Y1) }\end{array}$} & $\begin{array}{l}\text { Transaksi cepat selesai } \\
\quad\left(\mathrm{Y}_{4.1}\right)\end{array}$ & \multirow{3}{*}{$\begin{array}{l}\text { DeLone dan } \\
\text { McLean } \\
\text { (2003);Casalo } \\
\text { et al. (2008); } \\
\text { Jing dan In } \\
\text { Seong (2013) }\end{array}$} \\
\hline & $\begin{array}{l}\text { Menyenangkan } \\
\left(\mathrm{Y}_{4.2}\right)\end{array}$ & \\
\hline & $\begin{array}{l}\text { Merasa Aman } \\
\left(\mathrm{Y}_{4.3}\right)\end{array}$ & \\
\hline
\end{tabular}

Responden terdiri dari adalah Mahasiswa Fakultas Teknologi Informasi, Universitas Islam Kalimantan Banjarmasin guna mengetahui kepuasan mereka terhadap SIA Online.

\subsection{Arsitektur Model Konsep Penelitian}

Untuk mengatasi permasalahan yang terjadi pada sistem yang dijalankan saat ini, maka dibentuk sebuah sistem yang tentunya memiliki keunggulan, sistem tersebut digambarkan dengan diagram. Dengan diagram ini diharapkan akan mempermudah pemahaman terhadap hasil analisa, sehingga apabila terjadi kesalahan dapat diketahui sedini mungkin.

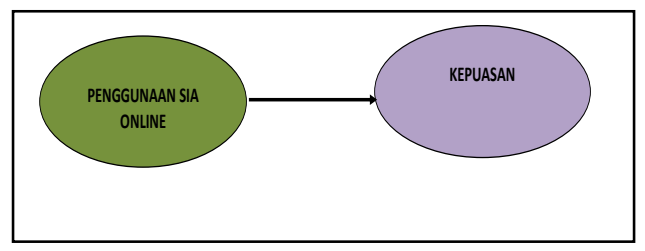

Gambar 3.1 Model Penelitian

Dengan diagram tersebut maka akan dirumuskan model hipotesis penelitian $\mathrm{H} 1$ : Penggunaan Sia_online berpengaruh signifikan dengan Kepuasan

\subsection{Metode Pengumpulan Data}

Penelitian ini menggunakan metode kuisioner untuk mendapatkan data yang diperlukan. Kuesioner merupakan teknik pengumpulan data yang dilakukan dengan cara memberi seperangkat pertanyaan atau pernyataan tertulis kepada responden untuk dijawab (Sugiyono, 2005).

\subsection{Variabel Penelitian}

Penelitian ini menggunakan dua jenis variabel yaitu variabel eksogen dan endogen. Variabel eksogen terdiri dari Penggunaan. Variabel endogen terdiri dari variabel Kepuasan

\section{Tabel Pemetaan Variabel Penelitian, Indikator dan Sumber}

\subsection{Teknik Analisis Data}

\subsubsection{Teknik Analisis Statistik Deskriptif}

Statistik deskriptif digunakan untuk memberikan deskripsi suatu data yang dilihat dari rata-rata (mean), modus, distribusi frekuensi dan persentase. Statistik deskriptif 
pada penelitian ini digunakan untuk memberikan gambaran mengenai demografi responden penelitian (umur, jenis kelamin, tingkat pendidikan) dan variabel-variabel yang diteliti.

\subsubsection{Teknik Analisis Inferensial}

Teknik analisis inferensial yang digunakan pada penelitian ini yaitu Partial Least Sqaure (PLS). Smart PLS Ver 3 berfungsi untuk mengkonfirmasi model teoritis melalui data empiris yang telah didapatkan. Penggantian faktor pada kombinasi linier dari

\begin{tabular}{|l|l|l|}
\hline & Kepuasan & Sia_Online \\
\hline X1.1 & & 0.734 \\
\hline X1.2 & & 0.918 \\
\hline X1.3 & & 0.909 \\
\hline X1.4 & & 0.873 \\
\hline X1.5 & & 0.836 \\
\hline Y1.1 & 0.917 & \\
\hline Y1.2 & 0.913 & \\
\hline Y1.3 & 0.889 & \\
\hline
\end{tabular}

variabel manifest (indikator) dapat lebih mudah dilakukan dengan menggunakan PLS. Terdapat beberapa tahapan untuk merancang permodelan hingga persamaan, dengan demikian akan memudahkan untuk dilakukan analisis data.

\subsubsection{Merancang Model Struktural}

Model struktural dirancang menggambarkan hubungan antar variabel laten pada PLS sesuai dengan hipotesis penelitian. variabel pada PLS dapat mengarah pada (a) normatif finalitas, (b) berdasarkan teori, (c) hasil penelitian empiris, (d) adopsi hubungan antar variabel dari bidang ilmu lainnya, (e) normative nonfinalitas, (f) rasionalitas. PLS berdasarkan rasionalitas melalui perancangan model struktural, perancangan model pengukuran, konstruksi diagram jalur, konversi diagram jalur ke persamaan, evaluasi goodness of fit, hingga pengujian hipotesis.

Berikut adalah model struktural yang dibentuk dari persamaan masalah

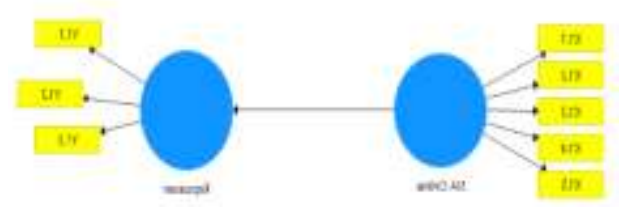

Gambar 3.2 Model Struktural

Keterangan

$\mathrm{X}_{1}$ : Sia Online

$\mathrm{X}_{1.1}$ : Mudah dipahami

$\mathrm{X}_{1.2}$ : Mudah digunakan

$\mathrm{X}_{1.3}$ : Mudah diimplementasi

$\mathrm{X}_{1.4}$ : Mudah dikendalikan

$\mathrm{X}_{1.5}$ : Mudah dilakukan maintenance

Y1: Kepuasan

$\mathrm{Y}_{1.1}$ : Transaksi cepat selesai

$\mathrm{Y}_{1.2}:$ Menyenangkan

$\mathrm{Y}_{1.3}$ : Merasa Aman

Menggunakan data sebagai berikut :

Dengan menggunakan PLS (Partial Least Square) versi 3.0, dan dengan perhitungan algorithm, maka didapatkan nilai-nilai sebagai berikut :

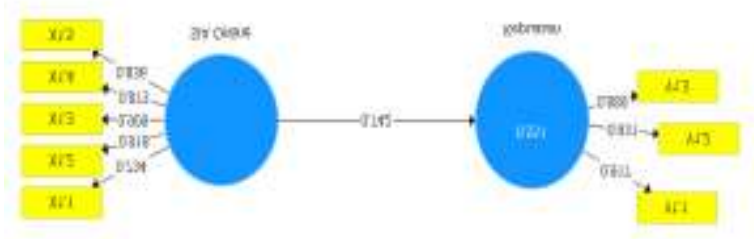

\section{Gambar 3.3 Output Calculate Alghoritm}

Output yang menjelaskan hubungan antara variable laten dengan indikatornya adalah sebagai berikut :

a. X1.1 (Mudah dipahami) memiliki hubungan sebesar 0.73 terhadap X1 (Sia_Online)

b. X1.2 (Mudah digunakan) memiliki hubungan sebesar 0.91 terhadap X1 (Sia_Online)

c. X1.3 (Mudah diimplementasi) memiliki hubungan sebesar 0.90 terhadap X1 (Sia_Online)

d. X1.4 (Mudah dikendalikan) memiliki hubungan sebesar 0.83 terhadap X1 (Sia_Online) 
e. X1.5 (Mudah dilakukan maintenance) memiliki hubungan sebesar 0.83 terhadap X1 (Sia_Online)

f. Y1.1 (Transaksi cepat selesai) memiliki hubungan sebesar 0.91 terhadap Y1 (Kepuasan)

g. Y1.2 (Menyenangkan) memiliki hubungan sebesar 0.93 terhadap Y1 (Kepuasan)

h. Y1.3 (Merasa Aman) memiliki hubungan sebesar 0.88 terhadap Y1 (Kepuasan)

Berdasarkan pada interpretasi tersebut, maka dapat dianalisis bahwasanya :

a. Mudah digunakan sangat mempengaruhi penggunaan Sia Online karena tingkat hubungan hampir $100 \%$, sedangkan Mudah dipahami pada sia online memiliki hubungan yang tidak terlalu besar dibandingkan dengan mudah digunakan, ini menunjukkan bahwa mudah dipahami tergantung dari individu yang menggunakan dan sudah menjadi tugas mereka untuk memahaminya.

b. Ketiga indikator dari kepuasan mendapatkan nilai yang besar maka dapat dikatakan bahwasanya indikator tersebut membuktikan bahwa Kepuasan berdasarkan kebutuhannya dipengaruhi oleh Transaksi Cepat selesai, Menyenangkan dan merasa Aman.

Output yang menjelaskan hubungan antar variabel laten :

Tabel Laten Variabel Correlation

\begin{tabular}{|l|l|l|}
\hline & Kepuasan & Sia_Oline \\
\hline Kepuasan & 1.000 & 0.742 \\
\hline Sia-Online & 0.742 & 1.000 \\
\hline
\end{tabular}

Sia Online (X1) memiliki pengaruh terhadap Kepuasan (Y1) sebesar 0.74

Berdasarkan pada interpretasi tersebut, maka dapat dianalisis bahwasanya , semua variabel laten dalam penelitian ini memiliki hubungan $70 \%$, maka dapat disimpulkan bahwa sanya semua variabel laten dalam penelitian ini memiliki hubungan yang cukup besar. Dan hubungan tersebut sesuai dengan model analisis dalam penelitian yang sudah digambarkan dalam penelitian ini.

Output yang menjelaskan pengaruh variable laten :

Path Coefficient

\begin{tabular}{|l|l|l|}
\hline & Kepuasan & Sia_Oline \\
\hline Kepuasan & & \\
\hline Sia-Online & 0.742 & \\
\hline
\end{tabular}

Sia-Online memiliki pengaruh terhadap kepuasan sebesar 0.742

Tabel AVE

\begin{tabular}{|l|lr|}
\hline & $\begin{array}{l}\text { Average } \\
\text { Extracted(AVE) }\end{array}$ & Variance \\
\hline Kepuasan & 0.833 \\
\hline Sia_online & 0.734 \\
\hline
\end{tabular}

Discriminant validity adalah membandingkan nilai square root of average variance extracted (AVE) setiap konstruk dengan korelasi antar konstruk lainnya dalam model, jika square root of average variance extracted (AVE) konstruk lebih besar dari korelasi dengan seluruh konstruk lainnya maka dikatakan discrimanant validity yang baik. Direkomendasikan hasil pengukuran harus lebih besar dari 0.50

Output yang menunjukkan akurasi,konsistensi dari ketepatan alat ukur Composite reliability merupakan uji reliabilitas dalam PLS yang mana menunjukkan akurasi,konsistensi dan ketepatan suatu alat ukur dalam pengukuran

Composite Reliability

\begin{tabular}{|l|l|l|}
\hline & $\begin{array}{l}\text { Composite } \\
\text { Reliability }\end{array}$ & \\
\hline Kepuasan & 0.937 & \\
\hline Sia_online & 0.917 & \\
\hline
\end{tabular}

Composite Reliability adalah kelompok indikator yang mengukur sebuah variabel 
memiliki reliabilitas komposit yang baik jika Composite Reliability $\geq 0.7$

Uji Validasi variabel dengan output sebagai berikut :

\begin{tabular}{|l|l|l|}
\hline & Kepuasan & Sia_Online \\
\hline X1.1 & 0,541 & 0.734 \\
\hline X1.2 & 0,699 & 0.918 \\
\hline X1.3 & 0.668 & 0.909 \\
\hline X1.4 & 0.566 & 0.873 \\
\hline X1.5 & 0.680 & 0.836 \\
\hline Y1.1 & 0.917 & 0.672 \\
\hline Y1.2 & 0.931 & 0.668 \\
\hline Y1.3 & 0.889 & 0.689 \\
\hline
\end{tabular}

Suatu indikator dinyatakan valid jika memiliki nilai korelasi diatas 0,70 , namum untuk loading 0,50 sampai 0.60 masih dapat diterima dengan melhat korelasi antara indikator dengan konstruknya

Tabel R Square

\begin{tabular}{|l|l|l|}
\hline & R Square & $\begin{array}{l}\text { R Square } \\
\text { Adjusted }\end{array}$ \\
\hline Kepuasan & 0.551 & 0,546 \\
\hline
\end{tabular}

Goodness of fit model diukur menggunakan $\mathrm{R}$-Square variabel laten dependen dengan interpretasi yang sama dengan regresi . Dengan menggunakan PLS ( Partial Least Square ) versi 3.0 dan dengan penghitungan bootstrapping untuk uji hipotesis. bootstrapping digunakan untuk menguji hipotesis (number of samples : 100 dan cases :100) maka didapatkan nilai-nilai sebagai berikut

\section{Output Bootsrap}

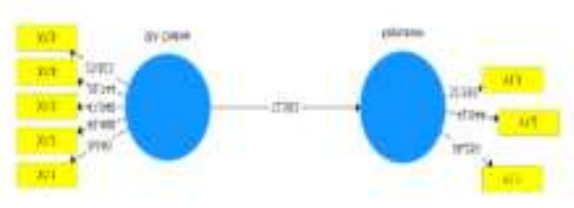

\section{Gambar 3.3 Output bootstrap}

\section{Outer Model T-Statistic}

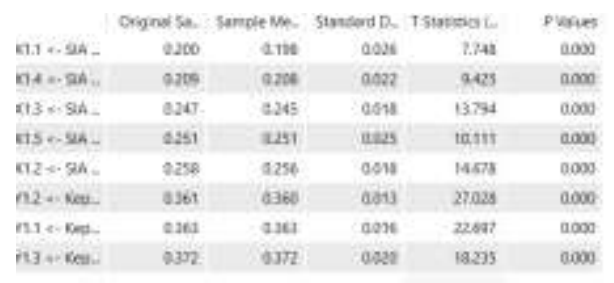

Total effect

\begin{tabular}{|l|l|l|l|l|l|}
\hline & $\begin{array}{l}\text { Origin } \\
\text { al } \\
\text { Sampl } \\
\text { e }\end{array}$ & $\begin{array}{l}\text { Sampl } \\
\text { e } \\
\text { Mean }\end{array}$ & $\begin{array}{l}\text { Standar } \\
\text { d } \\
\text { Deviatio } \\
\mathrm{n}\end{array}$ & $\begin{array}{l}\text { Standar } \\
\text { d Error }\end{array}$ & $\begin{array}{l}\text { T } \\
\text { Statisti } \\
\text { cs }\end{array}$ \\
\hline $\begin{array}{l}\mathrm{X} 1 \geq \mathrm{Y} \\
1\end{array}$ & 0,742 & 0,751 & 0,054 & 0.009 & 13,737 \\
\hline
\end{tabular}

Hubungan antara X1(Sia_online) dengan Y1( Kepuasan) adalah signifikan dengan T-statistik 13,7 (>1.96) dan nilai original sample estimate adalah positif yaitu 0,7 maka arah hubungan anata X1(Sia_online) dengan Y1( Kepuasan) adalah positif

T tabel dan $\mathrm{T}$ hitung

\begin{tabular}{|c|c|c|c|}
\hline Variabel & $\begin{array}{l}\mathrm{T} \\
\text { hitung }\end{array}$ & $\begin{array}{l}\mathrm{T} \\
\text { tabel }\end{array}$ & Kesimpulan \\
\hline $\begin{array}{l}\text { Penggunaan } \\
\text { Terhadap Mudah } \\
\text { dipahami }\end{array}$ & 8,64 & 1.96 & Signifikan \\
\hline $\begin{array}{l}\text { Penggunaan } \\
\text { Terhadap Mudah } \\
\text { digunakan }\end{array}$ & 45,48 & 1.96 & Signifikan \\
\hline $\begin{array}{l}\text { Penggunaan } \\
\text { Terhadap Mudah } \\
\text { diimplementasikan }\end{array}$ & 47,04 & 1.96 & Signifikan \\
\hline $\begin{array}{l}\text { Penggunaan } \\
\text { Terhadap Mudah } \\
\text { dikendalikan }\end{array}$ & 28,74 & 1.96 & Signifikan \\
\hline $\begin{array}{l}\text { Penggunaan } \\
\text { Terhadap Mudah } \\
\text { dilakukan } \\
\text { maintenance }\end{array}$ & 23,82 & 1.96 & Signifikan \\
\hline $\begin{array}{l}\text { KepuasanTerhadap } \\
\text { Transaksi mudah } \\
\text { selesai }\end{array}$ & 36,35 & 1.96 & Signifikan \\
\hline $\begin{array}{l}\text { KepuasanTerhadap } \\
\text { Menyenangkan }\end{array}$ & 42,64 & 1.96 & Signifikan \\
\hline $\begin{array}{l}\text { KepuasanTerhadap } \\
\text { Merasa Aman }\end{array}$ & 32,59 & 1.96 & Signifikan \\
\hline
\end{tabular}


Hasil Uji Hipotesis berdasarkan Bootstrapsing

\begin{tabular}{|l|l|l|l|}
\hline $\begin{array}{l}\text { Variabel } \\
\text { Bebas }\end{array}$ & $\begin{array}{l}\text { Variabel } \\
\text { Terikat }\end{array}$ & T hitung & Keterangan \\
\hline $\mathrm{X} 1.1$ & $\mathrm{X} 1$ & 0.73 & H1 diterima \\
\hline $\mathrm{X} 1.2$ & $\mathrm{X} 1$ & 0.91 & H1 diterima \\
\hline $\mathrm{X} 1.3$ & $\mathrm{X} 1$ & 0.90 & H1 diterima \\
\hline $\mathrm{X} 1.4$ & $\mathrm{X} 1$ & 0.87 & H1 diterima \\
\hline $\mathrm{X} 1.5$ & $\mathrm{X} 1$ & 0.83 & H1 diterima \\
\hline $\mathrm{Y} 1.1$ & $\mathrm{Y} 1$ & 0.91 & H1 diterima \\
\hline $\mathrm{Y} 1.2$ & $\mathrm{Y} 1$ & 0.93 & H1 diterima \\
\hline $\mathrm{Y} 1.3$ & $\mathrm{Y} 1$ & 0.88 & H1 diterima \\
\hline
\end{tabular}

\section{KESIMPULAN}

Berdasarkan dari temuan penelitian ini tentang pengaruh pengguna sistem informasik Akademik Online dengan kepuasan bahwa , adanya pengaruh yang signifikant antara penggunaan sia online dengan kepuasan mahasiswa terhadap pelayanan yang diberikan universitas. Dengan demikian semakin meningkatnya layanan pada sistem yang di sediakan terutama sia online maka kepuasan mahasiswa semakin meningkat, perlu adanya penelitian yang lebih lanjut dengan menambah variabel pelayanan lainnya, misalnya pelayanan administrasi, pelayan pada sarana dan prasarana dan lain sebagainya

\section{DAFTAR PUSTAKA}

Ajzen, I. (1988). Attitudes, Personality, and Behavior. Wales: Dorsey Press.
DeLone, W., \& McLean, E. (2003). The DeLone and McLean Model of Information System Success: A TenYear Update. Journal of Management Information Systems, 4 (19), 9-30.

Henderson J. C. dan Venkatraman N. (1993) Strategic Alignment: A Model for Organizational Transforming via Information Technology. New York: Oxford University Press.

Jogiyanto, H. (2008). Sistem Informasi Keperilakuan. Yogjakarta: Andi.

Larsen, T., Sorebo, A., \& Sorebo, O. (2009). The Role of Task-Technology Fit as Users' Motivation to Continue Information System Use. Computer in Human Behavior. 25 (3), 778-784.

McKeen, James; Tor Guimaraes dan James C Whetherbe. 1994 "The Relationship Between Participation and User Satisfaction of Four Contigency Factors". MIS Quarterly. ABI/INFORM Global.

Syukron Anas ;Wing Wahyu Winarno dan Hanif Al Fatta,2017" Evaluasi tata kelola teknologi informasi akademik Stmik dipanegara makassar 